\title{
Investigating the Effect of Chemical Treatment on the Constituents and Tensile Properties of Sisal Fibre
}

\author{
I.O. Oladele*, J.A. Omotoyinbo and J.O.T. Adewara \\ Metallurgical and Materials Engineering Department, \\ Federal University of Technology, Akure. \\ Ondo State, Nigeria. \\ Affiliated to African Materials Science and Engineering Network (AMSEN). \\ *Corresponding Author: wolesuccess2000@yahoo.com
}

\begin{abstract}
This work was carried out to investigate the effect of chemical treatment on the constituents and tensile properties of sisal fibre (Agave Sisalana). Sisal leaves were cut and buried underground close to the stream and were wetted with water regularly in order to ensure proper fermentation for about 15 days. The fermented leaves were washed and sun dried. The dried sisal fibre obtained was treated mechanically with chemicals after which the percentages of their constituents were characterized and, their tensile properties determined with Instron universal tensile testing machine. The results show that the chemical treatments enhance the removal of lignin and hemicelluloses which are detrimental to the bonding strength of composite produced from natural fibres except that of sample treated with alkaline peroxide. The results of the tensile test revealed that sample treated sequentially with $\mathrm{KOH}$, acetic acid, $\mathrm{NaCl}$ and $\mathrm{HCl}$ has the best tensile properties followed by the sample treated with alkaline peroxide.
\end{abstract}

Keywords: Investigate chemical treatment, constituents, tensile properties, and sisal fibre.

\section{INTRODUCTION}

There is a growing interest in the use of natural fibres as reinforcement for thin sheet cement composites [1] and thermoplastic matrix composites [2]. Natural fibres generally have poor mechanical properties compared with synthetic fibres but their use as reinforcement material has been adopted since the beginning of mankind to make straw reinforced huts and other 
articles [3]. However, the main advantages of these fibres are their availability in large quantities in many countries, low density, low cost and ease of manufacture.

In the last decade, extensive research work has been carried out on the natural fibre reinforced composite materials. Natural fibres can be used to reinforce polymers to obtain light and strong materials. Natural fibres from plants are beginning to find their way into commercial applications such as in automotive industries and household applications, [4].

Due to the relatively high cost of synthetic fibres such as, glass, plastic, carbon and Kevlar used in fibre reinforced composites, and the health hazards of asbestos fibres, it has become necessary to explore natural fibres. Natural fibres are produced from renewable resources, are biodegradable and relatively inexpensive compared to the traditionally used synthetic fibres. Fibres of this type, for instance, hemp and flax, are successfully used as packaging material, interior panels in vehicles, and building components, among others. Also, natural fibres like banana, sisal, hemp and flax, jute, coconut, local fibres and oil palm [5-11] have attracted scientists and technologists for applications in consumer goods, low-cost housing and other civil structures.

The fibre/matrix interface has an important role in the micromechanical behaviour of composites. One difficulty that has prevented the use of natural fibres is the lack of good adhesion with the polymeric matrix. In particular, the large moisture sorption of natural fibres adversely affects adhesion with hydrophobic matrix material leading to premature ageing by degradation and loss of strength. To prevent this phenomenon, fibre surface properties have been modified in order to promote adhesion [12]. To reinforce thermoplastic composites, blue agave fibres were modified via esterification reaction [13]. The mechanical properties characterization of these fibres showed a change in the elastic modulus and an improvement in the impact resistance [2]. There are, however, several separation of fibre processing techniques such as mechanical or chemical pulping, whereby the lignin is degraded and dissolved, leaving most of the cellulose and hemicelluloses in the form of fibres. This generally has an important effect on both mechanical and chemical properties of the fibres.

Resently, natural fibres have proved to be effective reinforcement as simple fillers in thermoplastic and thermoset matrix composites for automotive sectors [14]. A number of investigations have been conducted on several types of natural fibres such as kenaf, hemp, flax, bamboo, and jute to study the effect of these fibres on the mechanical properties of composite materials. This work was carried out to investigate the effect of chemical treatment on the chemical constituents and the tensile properties of sisal fibre (Agave Sisalana).

\section{MATERIALS AND METHOD}

\subsection{Materials}

The materials that were used are sisal leaves, distilled water, hydrogen chloride, hydrogen peroxide, potassium hydroxide and acetic acid. 


\subsection{Equipment}

Weighing balance, shaker water bath, beakers, furnace, crucible, instron universal tensile testing machine.

\subsection{Method}

\subsubsection{Preparation of Materials}

The sisal fibre used was obtained from the plant leaves. The leaves were cut and buried under ground for 15 days so as to allow fermentation to take place. For the reaction to take place normally, the leaves were buried close to stream of water and are watered daily. The fermented leaves were washed after which they were sun dried.

\subsubsection{Chemical Treatment}

Cellulose micro fibrils were prepared using different combinations of chemical and mechanical treatments. Three different treatments were carried out on different samples while some was left as control. The treatment was carried out as follows:

Mass of Fibre used: 120g sisal fibre was divided into four equal mass of $30 \mathrm{~g}$ each.

\subsubsection{Sample A}

The sample was treated with $0.5 \mathrm{M} \mathrm{NaOH}$ solution $(450 \mathrm{ml})$ inside shaker water bath at $40^{\circ} \mathrm{C}$ for 10 hours. The insoluble residue was treated with $0.5 \mathrm{M} \mathrm{NaOH}$ and $3 \mathrm{wt} \% \mathrm{H}_{2} \mathrm{O}_{2}$ solution $(400 \mathrm{ml})$ at $45^{\circ} \mathrm{C}$ for 8hours and was finally treated with $2 \mathrm{M} \mathrm{NaOH}$ solution $(400 \mathrm{ml})$ at $55^{\circ} \mathrm{C}$ for 2 hours

\subsubsection{Sample B}

The sample was treated with $0.5 \mathrm{M} \mathrm{NaOH}$ solution $(450 \mathrm{ml})$ inside shaker water bath at $40^{\circ} \mathrm{C}$ for 10 hours. The insoluble residue was treated with $0.5 \mathrm{M} \mathrm{NaOH}$ and $3 \mathrm{wt} \% \mathrm{H}_{2} \mathrm{O}_{2}$ solution $(400 \mathrm{ml})$ at $45^{\circ} \mathrm{C}$ for 8 hours and finally treated with $2 \mathrm{M} \mathrm{HCl}(400 \mathrm{ml})$ at $70^{\circ} \mathrm{C}$ for 2 hours in order to remove mineral traces.

\subsubsection{Sample C}

This sample was treated with $5 \mathrm{wt} \% \mathrm{KOH}$ solution (450ml) inside shaker water bath at $40^{\circ} \mathrm{C}$ for 10 hours. The insoluble residue was delignified with $1 \% \mathrm{NaCl}$ solution (400ml) at $\mathrm{pH} 3$, and adjusted with $10 \mathrm{wt} \%$ acetic acid at $70^{\circ} \mathrm{C}$ for 1 hour. Another treatment with $\mathrm{KOH}$ solution (250ml) under the same conditions as the first step was used. Finally, a $1 \mathrm{wt} \% \mathrm{HCl}$ solution $(300 \mathrm{ml})$ at $80^{\circ} \mathrm{C}$ for 2 hours was used to remove mineral traces. 


\subsubsection{Control Sample}

The untreated sample was used as the control.

\subsection{Determination of Chemical Constituents}

\subsubsection{Determination of Lignin Content by Gravimetric Method}

$1.5 \mathrm{~g}$ of the sample was weighed and $72 \% \mathrm{H}_{2} \mathrm{SO}_{4}$ was added and soaked for 2hours. 8\% $\mathrm{H}_{2} \mathrm{SO}_{4}$ was later added and the solution reflux for 4hours. The residue was filtered with purpling cloth and washes severally with hot water. The crucible to be used was weighed and the sample was scraped into it. The sample was oven dried at $105^{\circ} \mathrm{C}$ for 2 hours and was cooled inside desiccators after which the weight was taken. The sample was later ashed in the furnace at $550^{\circ} \mathrm{C}$ for 3hours after which it was cooled inside the desiccators and finally weighed. The \% Lignin was later calculated as follows;

$\%$ Lignin $=\underline{\mathrm{W}}_{\underline{2}} \frac{-\mathrm{W}_{1}}{\mathrm{Ws}} \times 100$

Where,

$\mathrm{W}_{1}=$ weight of the ash sample + crucible

$\mathrm{W}_{2}=$ weight of the oven dried sample +crucible

Ws =initial weight of the dried extractive free sample.

\subsubsection{Determination of Cellulose Content}

$1 \mathrm{~g}$ of the sample was weighed and place inside a beaker where $25 \mathrm{ml}$ of $80 \%$ acetic acid, $1 \mathrm{ml}$ of concentrated nitric acid and 4 glass beads was added and reflux for 20minutes on cellulose refluxing apparatus. The fibre was washed into 50ml centrifuge tube with hot $95 \%$ ethanol and centrifuge at 18000r.m.p for 5minutes. The liquid is decanted, 95\% ethanol is added, stirred and centrifuge for another 5minutes. Liquid is decanted; sample washed with hot $95 \%$ ethanol and filter by suction. Sample is washed three times with hot benzene, two times with 95\% ethanol and once with ether. The sample was placed inside a weighed crucible that was later placed in the oven maintained at $105^{\circ} \mathrm{C}$ for 1 hour. The crucible was latter cool in desiccators and weighed. The crucible was placed inside the furnace that was maintained at $550^{\circ} \mathrm{C}$ for 4 hours; cool in desiccators and weigh for ash weight. The percentage cellulose was calculated as follows;

$\%$ Cellulose $=\underline{\mathrm{W}_{2}} \underline{\underline{-}-\mathrm{W}_{1}} \underset{\mathrm{W}_{\mathrm{S}}}{ } \mathrm{X} 100$

Where,

$\mathrm{W}_{1}=$ weight of crucible + sample after ashing.

$\mathrm{W}_{2}=$ weight of crucible + sample after drying

$\mathrm{W}_{\mathrm{S}}=$ weight of sample 


\subsubsection{Determination of Hemicelluloses}

$0.5 \mathrm{~g}$ of sample were weighted into two different beakers denoted as A and $\mathrm{B}$. $5 \% \mathrm{KOH}$ was added to the sample in flask A while $24 \% \mathrm{KOH}$ was added to the sample in flask B and both samples were allowed to stand for 2hours. The mixtures were filter with purpling cloth, washed with additional $\mathrm{KOH}$ solution of their respective percentages and the filtrate is received into two different beakers (A and $\mathrm{B}$ ). The hemicelluloses are then quantitatively precipitated by the addition of alcohol (ethanol). The precipitated hemicelluloses were isolated by centrifuging for 10minutes. The isolated hemicellulose was washed with alcohol (ethanol) and ether and finally transfers into two different crucibles (A and B). The samples were dried in oven for 2 hours at $105^{\circ} \mathrm{C}$. After this, they were transferred into desiccators and allowed to cool for 30minutes after which their weights were taken. The samples were also placed inside the furnace maintained at $550^{\circ} \mathrm{C}$ for 3hours after which they were cooled inside the desiccators and weighed. The weight of the precipitate $A$ was calculated $\left(\mathrm{W}_{\mathrm{A}}\right)$ while the weight of the precipitate $B$ was also calculated $\left(\mathrm{W}_{\mathrm{B}}\right)$. Hence the percentage hemicelluloses compositions of the samples were calculated as follows;

$\%$ Hemicelluloses $(\mathrm{A})=\underline{\mathrm{W}_{\underline{\mathrm{A}}}} \underset{\mathrm{W}_{2}}{ } \times 100$

Where,

$\mathrm{W}_{\mathrm{A}}=$ dried weight of hemicelluloses precipitate $\mathrm{A}$

$\mathrm{W}_{2}=$ dried weight of the hemicelluloses sample

$\%$ Hemicelluloses $(B)=\underline{\mathrm{W}}_{\underline{\mathrm{B}}} \times 100$

Where,

$\mathrm{W}_{\mathrm{B}}=$ dried weight of hemicelluloses precipitate $\mathrm{B}$

$\mathrm{W}_{2}=$ dried weight of the hemicelluloses sample

\subsubsection{Determination of the Tensile Properties of the Fibre}

The tensile properties were determined from the instron universal tensile testing machine. This was carried out by fixing the sample on the grips of the machine after which it was operated automatically. As the extension proceeds, the graph and some readings were displayed on the computer.

\section{RESULTS AND DISCUSSION}

\subsection{Variation of the Constituents with Chemical Treatments of the Sisal Fiber}

The results of the constituents of the different fibres were as shown in table1and Figure1 below. 
Table1: Constituents of the Sisal Fibres and their $\mathrm{pH}$ Values.

\begin{tabular}{|l|l|l|l|l|l|}
\hline Fibre & Cellulose (\%) & Ash (\%) & Lignin (\%) & $\begin{array}{l}\text { Hemicelluloses } \\
\mathbf{( \% )}\end{array}$ & Ph \\
\hline Control & 42.85 & 2.34 & 18.65 & 25.28 & 5.86 \\
\hline A & 31.40 & 2.10 & 20.24 & 30.04 & 8.52 \\
\hline B & 17.61 & 1.16 & 5.87 & 9.80 & 3.43 \\
\hline C & 15.93 & 1.02 & 8.92 & 11.26 & 4.69 \\
\hline
\end{tabular}

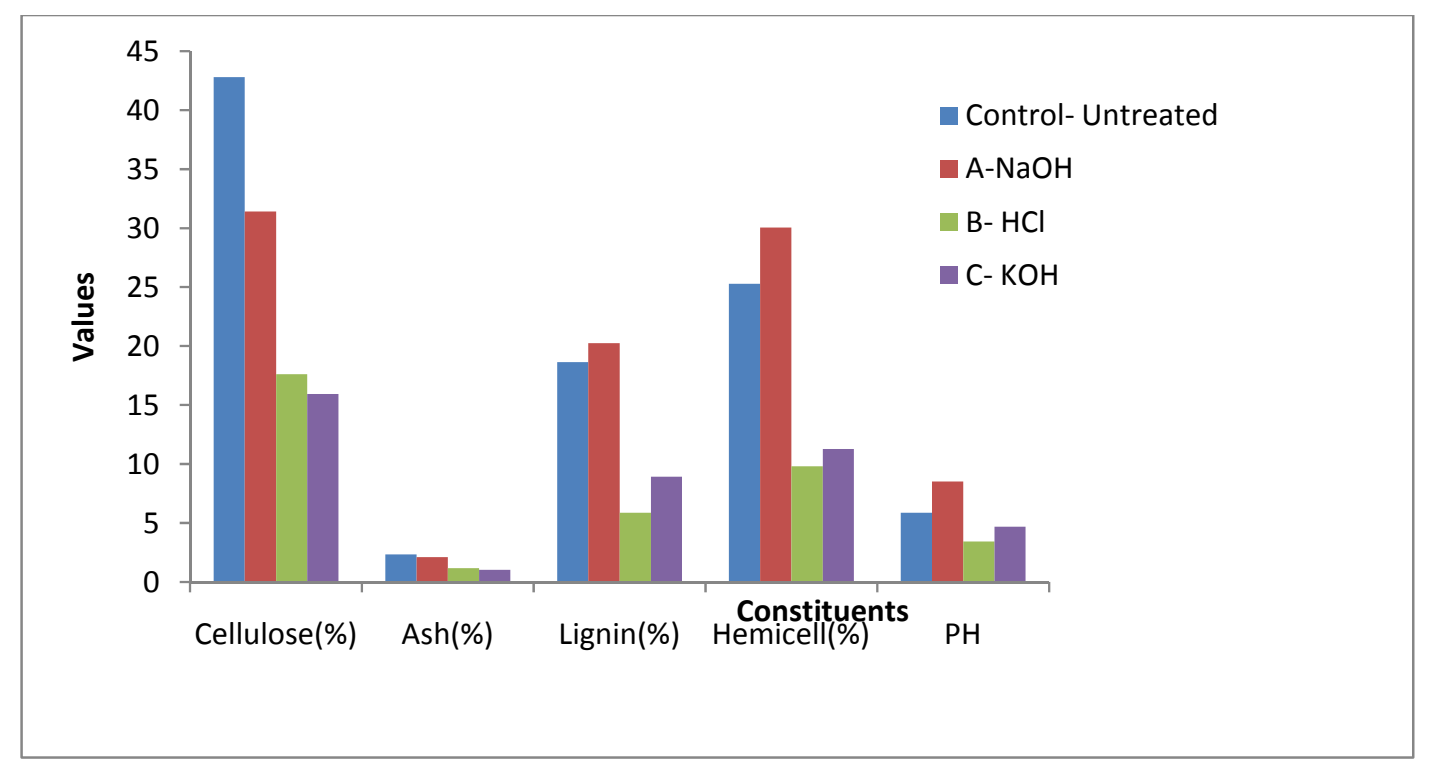

Figure1: Plots of the Sisal Constituents and PH Values for both Treated and Untreated Sisal Fibres.

\subsection{Discussion}

During chemical treatments, constituent like hemicelluloses was hydrolyzed by the action of alkaline solutions, whereas lignin was removed during additional steps using sodium chloride or hydrogen peroxide. To improve and achieve an acceptable dispersion level in the solution, mechanical homogenization with shaker water bath was also used for all samples.

The treatments with the exception of alkaline peroxide (AP), sample A, contributed to the removal of hemicelluloses and lignin contents as shown in Table1 and Figure 1. The resistance to extraction with alkaline of the sugars that are the main constituents of hemicelluloses is due to the association between xyloglucan and cellulose that is very strong. Xyloglucan probably binds not only to the surface of cellulose microfibrils, but it can also be entrapped within the microfibrils [15]. Xylans, xyloglucans and glucomannans are all able to bind onto cellulose fibrils in a manner similar to the interchain bonding of cellulose itself. 
[16] demonstrated that the method with the sodium chlorite was more efficient than that with hydrogen peroxide to remove lignin.

From the results, it was observed that the lignin and hemicelluloses constituents as well as their $\mathrm{pH}$ values have the same response to the chemical treatments. The results show higher percentages of lignin and hemicelluloses in sample A that was treated with alkaline peroxide more than that of the control sample while samples B treated with $\mathrm{HCl}$ in addition to the alkaline peroxide and $\mathrm{C}$ treated with $\mathrm{HCl}$ in addition to $\mathrm{KOH}$, acetic acid and $\mathrm{NaCl}$ have lower values. However, it was observed that sample B has the least values for both constituents. This result was in agreement with the results from the above mentioned researchers.

Also, the results revealed the response of the cellulose and the ash contents as well as the $\mathrm{pH}$ values of the fibres to the chemical treatments. It was observed that, the percentages of the constituents as well as their $\mathrm{pH}$ values reduce in the same order from Control down to $\mathrm{C}$ for both constituents as shown in Table1 and Figure1.

The bonding nature between the fibre and the matrix depends on the atomic arrangement, chemical properties of the fibre and the chemical constitution of polymeric matrix. However, in the natural fibre composite, cellulose is the principal coupling agent in the polymer/fibre bonding. On the other hand, lignin acts as an obstruction to the coupling agent diffusion, preventing good adhesion [17].

\subsubsection{Variation of Tensile Properties with Chemical Treatments of the Sisal Fiber}

The results of the tensile properties obtained were shown in Figures 2-9.

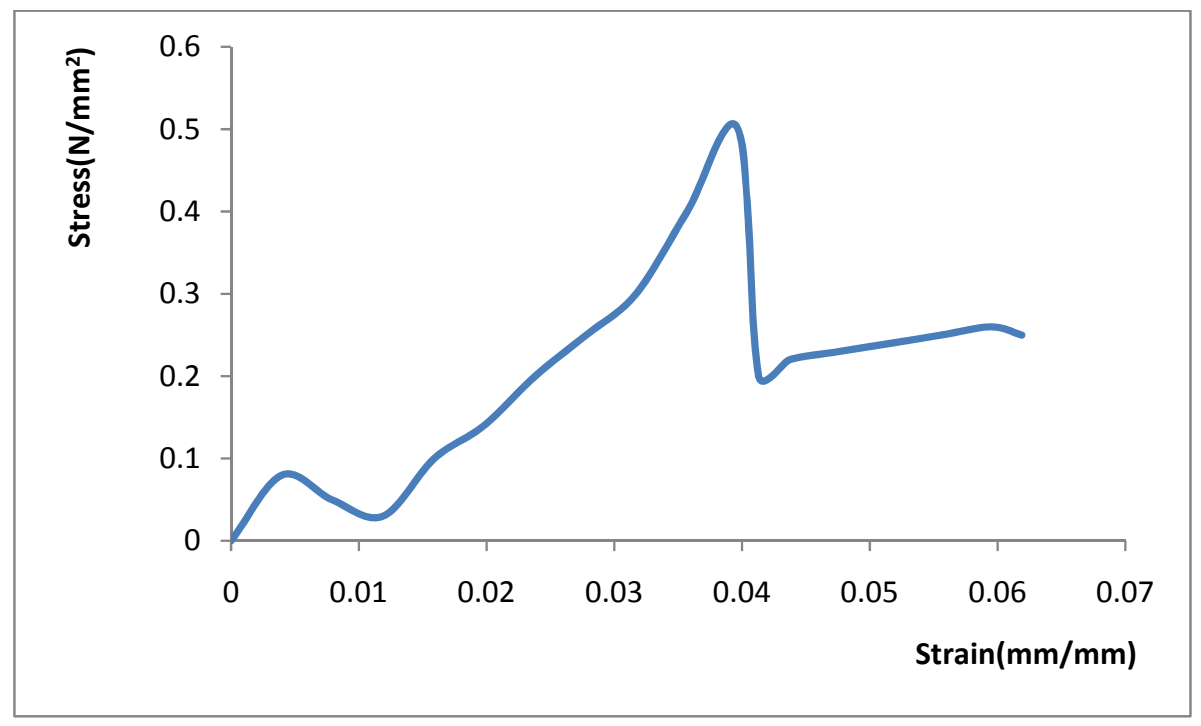

Figure 2: Plot of Stress against Strain for the Untreated Sample. 


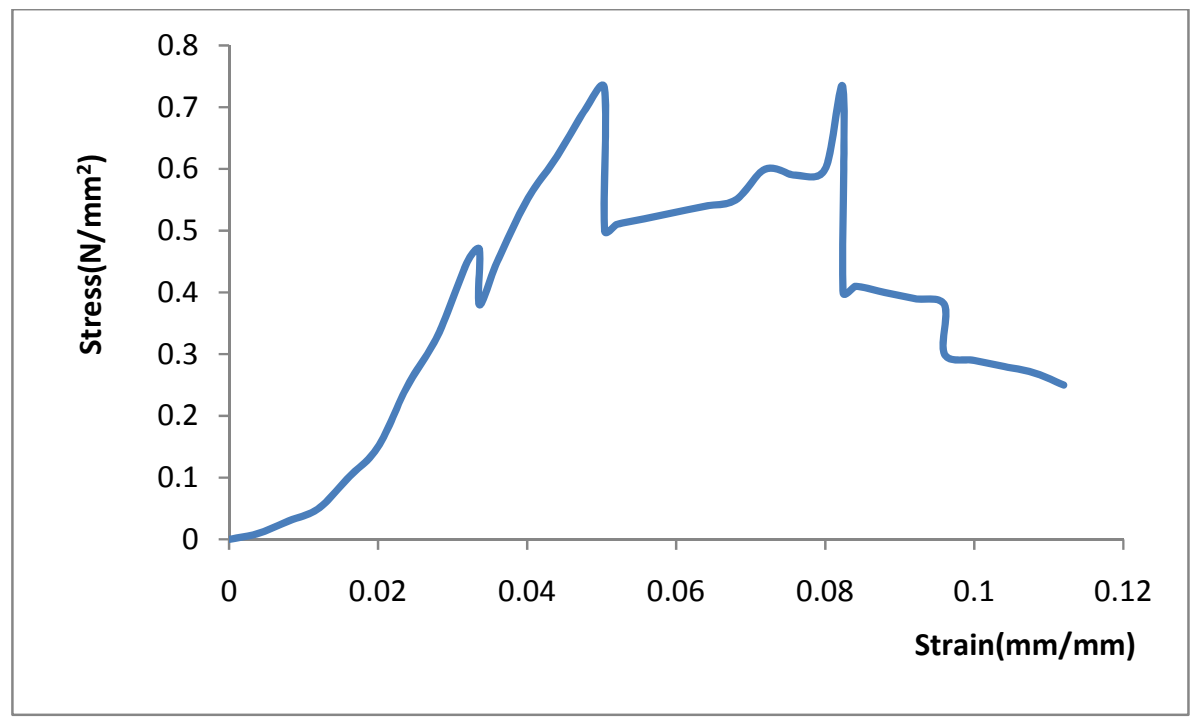

Figure 3: Plot of Stress against Strain for Treated Sample A (NaOH).

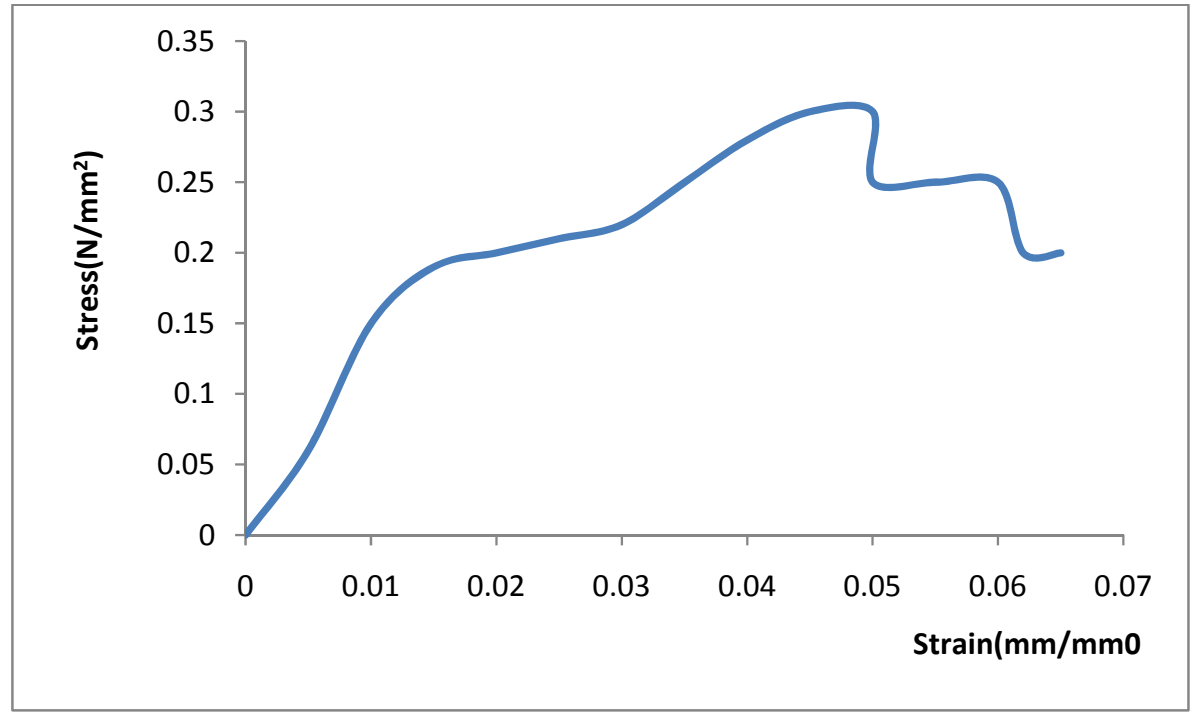

Figure 4: Plot of Stress against Strain for Treated Sample B (HCl). 


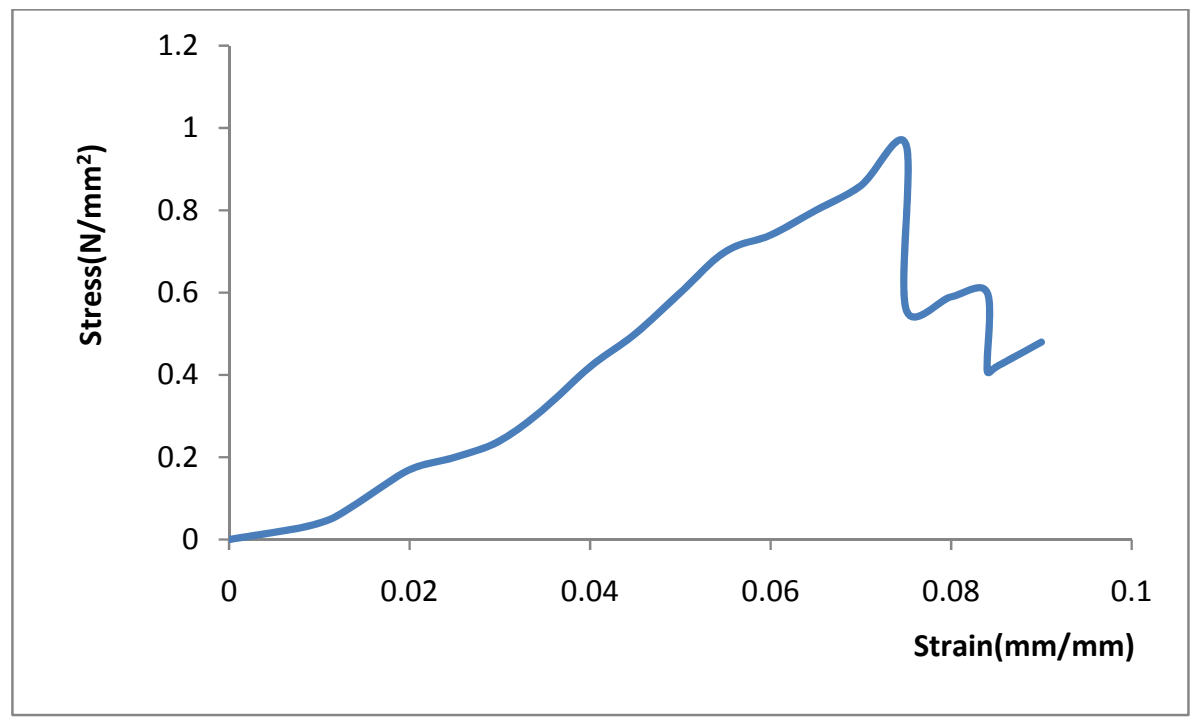

Figure 5: Plot of Stress against Strain for Treated Sample C (KOH).

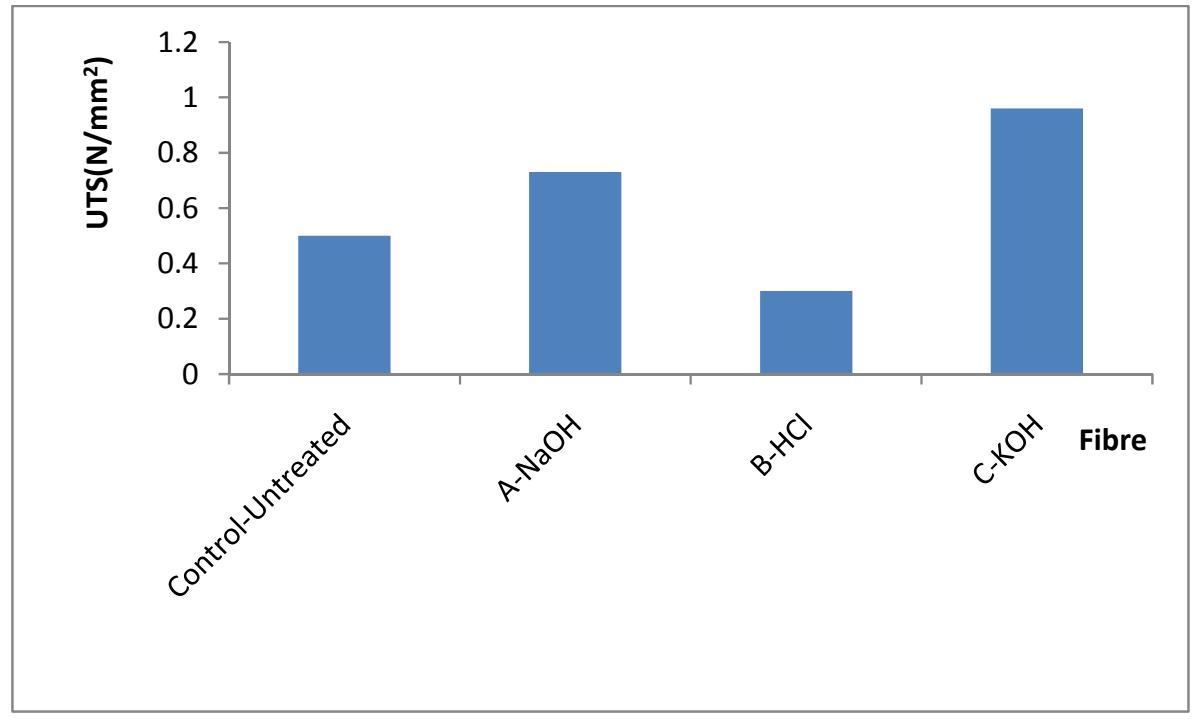

Figure 6: Plot of UTS against Fibres for both Treated and Untreated Samples. 


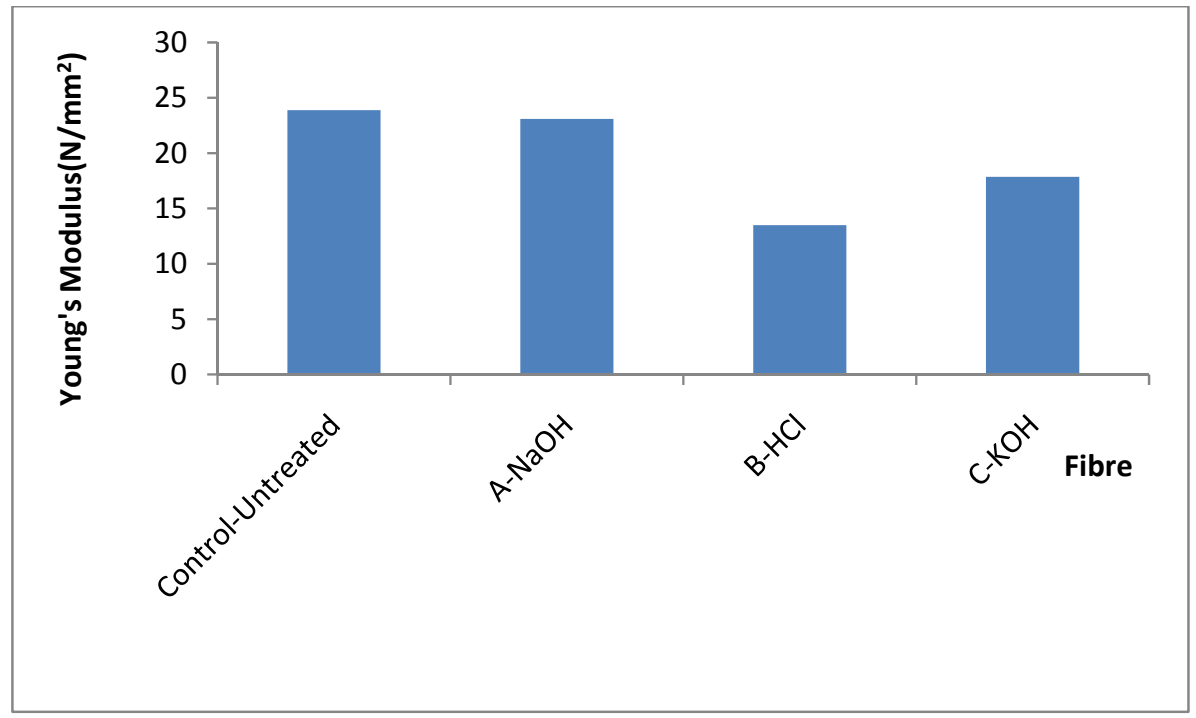

Figure 7: Plot of Young's Modulus against Fibres for both Treated and Untreated Samples.

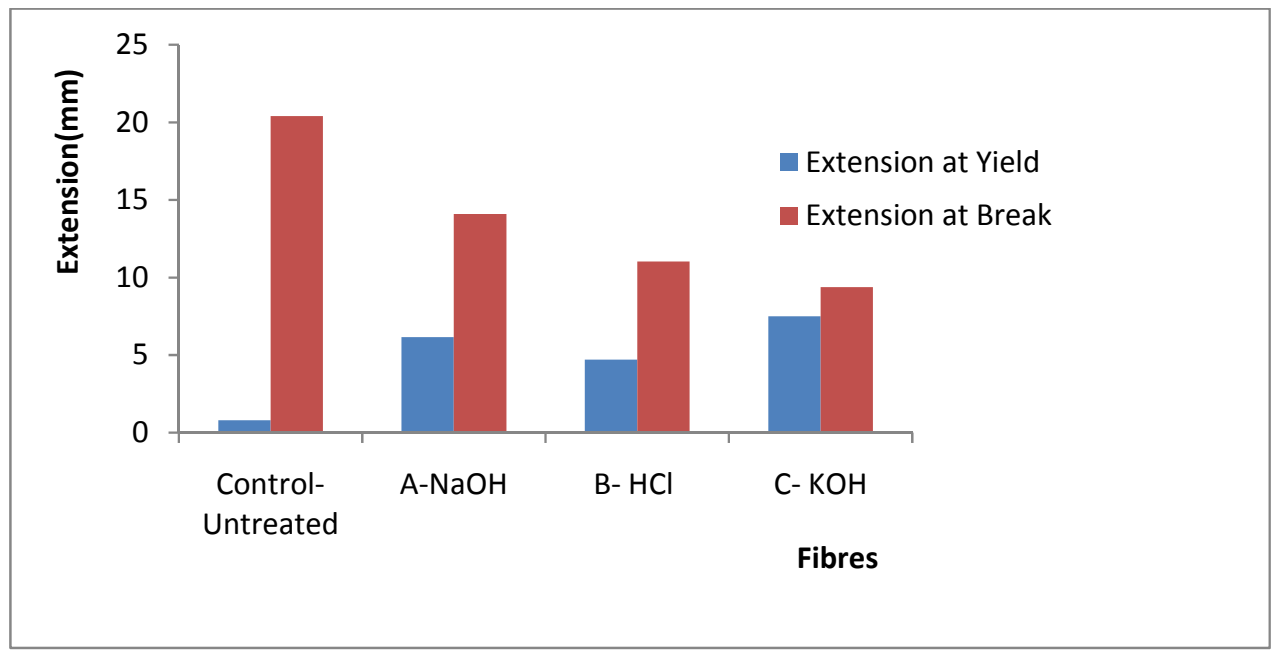

Figure 8: Plot of Extension against Fibres for both Treated and Untreated Samples. 


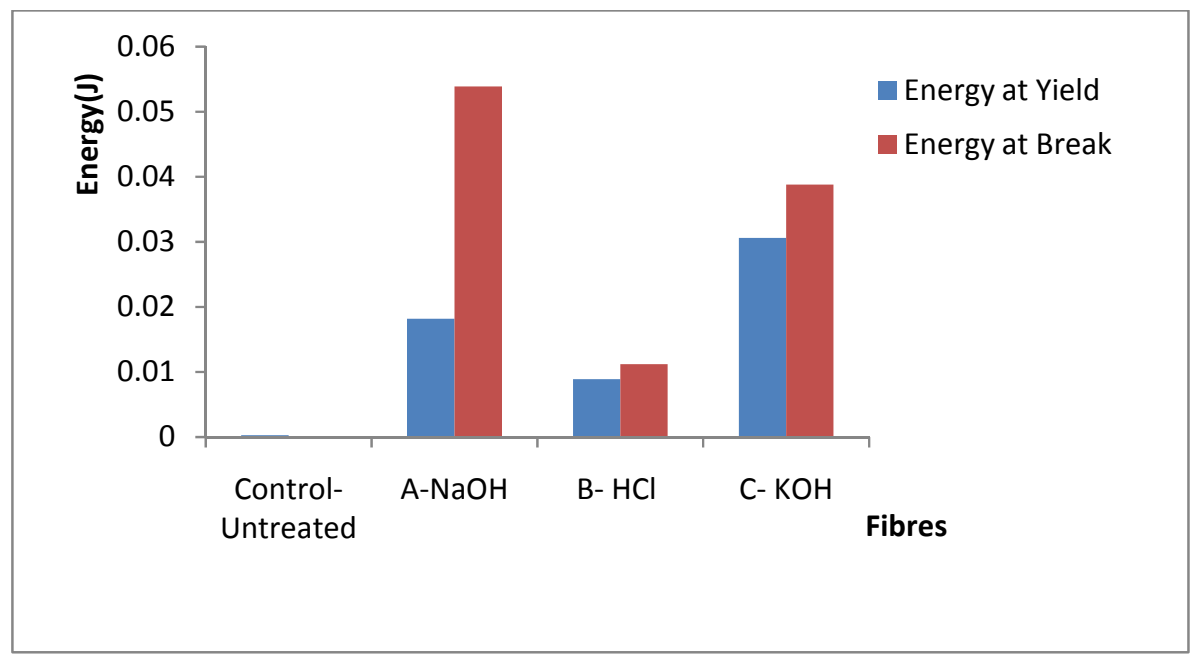

Figure 9: Plot of Energy against Fibres for both Treated and Untreated Samples.

\subsubsection{Response of the Fibers to Tensile Stress and UTS}

The results revealed the response of the fibres to tensile stress and UTS in Figures 2-6. It was observed that sample treated with combination of $\mathrm{KOH}, \mathrm{CH}_{3} \mathrm{COOH}, \mathrm{NaCl}$ and $\mathrm{HCl}$ that was coded as C-KOH has the highest UTS of $0.96 \mathrm{~N} / \mathrm{mm}^{2}$ followed by sample treated with combination of $\mathrm{NaOH}$ and $\mathrm{H}_{2} \mathrm{O}_{2}$ that was coded as A-NaOH with a value of $0.73 \mathrm{~N} / \mathrm{mm}^{2}$. However the untreated sample has higher UTS of $0.5 \mathrm{~N} / \mathrm{mm}^{2}$ than sample treated with combination of $\mathrm{NaOH}, \mathrm{H}_{2} \mathrm{O}_{2}$ and wash with $\mathrm{HCl}$ which was coded as $\mathrm{B}-\mathrm{HCl}$, its UTS was 0.3 $\mathrm{N} / \mathrm{mm}^{2}$.

\subsubsection{Young's Modulus of the Fibres}

The results of the Young's modulus of elasticity of the fibres were shown in Figure 7. The untreated sample has the best modulus of $23.89 \mathrm{~N} / \mathrm{mm}^{2}$ followed by sample A-NaOH with a close value of $23.089 \mathrm{~N} / \mathrm{mm}^{2}$ Sample C-KOH was next with a value $17.852 \mathrm{~N} / \mathrm{mm}^{2}$. Again, sample B-HCl has the least value of $13.486 \mathrm{~N} / \mathrm{mm}^{2}$. Young's modulus is the slope of the stress-strain curve within the range of proportionality before yield. Yield stress is defined as the stress at which materials experience a major micro structural deformation while the breaking stress is the stress at which materials failed. At the yield stress, a large amount of deformation takes place at constant stress [18].

\subsubsection{Response of the Fibers to Extension and Tensile Strain.}

The response of fibers to the extension at yield and at break was shown in Figure 8. The results showed that sample $\mathrm{C}-\mathrm{KOH}$ has the best extension of $7.5048 \mathrm{~mm}$ before it yield followed by sample A-NaOH with a value of $6.1597 \mathrm{~mm}$. Yielding Point is defined as the point at which materials experience a major deformation at the microstructural level. It is a point where additional strain occurs without any increase in stress load on the material, [19].However, the extension at break revealed that the untreated sample that was refer to as 
the control has the highest value of extension $(20.4089 \mathrm{~mm})$ before breaking followed by sample A-NaOH with a value of $14.0959 \mathrm{~mm}$. This shows that these samples can withstand the load generating the stress that will cause the materials to fail for longer period after yielding than sample $\mathrm{C}-\mathrm{KOH}$ with the highest extension before yielding and UTS respectively. The breaking load is the load that brings about material failure, [20].

\subsubsection{Response of the Fibers to Energy}

Figure 9 shows the response of the materials to the absorbed energy before yield and failure. The energy parameter denotes the resilience of the materials. From the results, it was observed that sample $\mathrm{C}-\mathrm{KOH}$ posses the highest energy of $0.0306 \mathrm{~J}$ before yielding followed by sample A-NaOH which has a value of 0.0182J. However at break, it was observed that sample A- $\mathrm{NaOH}$ posses the highest value of $0.0539 \mathrm{~J}$ while sample $\mathrm{C}-\mathrm{KOH}$ followed with a value of $0.0388 \mathrm{~J}$.

\section{CONCLUSION}

The results of the research have shown that;

- Chemical treatment has been found to improve the tensile properties of the sisal fiber.

- Chemical treatment has been found to be effective in this respect by removing the deleterious constituents such as lignin, hemicelluloses and ashes which affect the bonding strength between the sisal fiber and the polyester matrix.

- The chemicals applied in this work are combinations of $\mathrm{NaOH}, \mathrm{H}_{2} \mathrm{O}_{2} \mathrm{KOH}$, $\mathrm{CH}_{3} \mathrm{COOH}, \mathrm{NaCl}$ and $\mathrm{HCl}$ as follows:

$>$ Combination I: $\mathrm{NaOH}$ and $\mathrm{H}_{2} \mathrm{O}_{2}$ with $\mathrm{NaOH}$ wash

$>$ Combination II: $\mathrm{NaOH}, \mathrm{H}_{2} \mathrm{O}_{2}$ with $\mathrm{HCl}$ wash

$>$ Combination III: $\mathrm{KOH}, \mathrm{CH}_{3} \mathrm{COOH}, \mathrm{NaCl}$ with $\mathrm{HCl}$ wash

- $\quad$ Samples treated with Combination III gave the best tensile strength properties followed by the samples treated with Combination I.

- However, the untreated fiber produced the best extension before fracture.

\section{ACKNOWLEDGEMENTS}

I wish to acknowledge the following organisations for their support. They are Regional Initiative in Science Education (RISE), Science Initiative Group (SIG) and African Materials Science and Engineering Network (AMSEN). 


\section{REFERENCES}

1. Pelet A.,Sueki S.and Mobasher B (2006) Mechanical Properties of Hybrid Fabrics in Pultruded Cement Composites, $16^{\text {th }}$ European Conference of Fracture, Special Symposium Measuring Monitoring and Modelling Concrete Properties Alexandrroupolis, Greece.

2. Bessadok A.,Langevin D., Gouanve F., Chappey C., Roudesli S.,Marais S.,(2008),Study of Water Sorption on Modified Agave Fibres,Carbohydrate Polymers, Elsevier,76,pp 74-85.

3. Benjamin C. Tobias, (1990),Fabrication and Performance of Natural Fiber-Reinforced Composite Material, 35th. Int. SAMPLE Symposium, pp 970-387.

4. Wallenberger F.T., and Weston N., (2004), Natural Fibers, Plastics and Composite Natural,Material Source Book from C.H.I.P.S. Texas.

5. Idicula M., Malhota S.K., Joseph K., Thomas S., (2005), Dynamic Mechanical Analysis of Randomly Oriented Intimately mixed Short Banana/Sisal Hybrid Fibre Reinforced Polyester Composites, Composites Science and Technology, 67(7-8), pp 1077-1087.

6. Jacob M., Thomas S., Varughea K.T., (2004), Mechanical Properties of Sisal/Oil Palm Hybrid Fibre Reinforced Natural Rubber Composites, Composites Science and Technology, 64, pp 955-965.

7. Hautala M., Pasila A., Pirila J., (2004),Use of Hemp and Flax in Composite Manufacture: a search for new production methods, Composite Part A, 35, pp 11-16.

8. Chand N., Dwivedi U.K., (2006),Effect of Coupling Agent on Abrasive Wear Behaviour of Chopped Jute Fibre-Reinforced Polypropylene Composites, Composites Science and Technology, 261, pp1057-1063.

9. Brahmakumar M., Pavithran C., Pillai R.M., (2005),Coconut Fibre Reinforced Polyethylene Composites: effect of natural waxy surface layer of the fibre on fibre/matrix interfacial bonding and strength of composites, Material Processing Technology , 65(3-4),pp 563-569.

10. Oladele,I.O. and Adewuyi B.O. (2008) Development of Automobile Gaskets from Local Fibres, Journal of Science and Technology, Vol 28 No 3, p152-157.

11. Yousif B.F.,EL-Tayeb N.S.M.,(2007), The Effect of Oil Palm Fibres as Reinforcement on Tribological Performance of Polyester Composites, Surface Review Letter, Composites Science and Technology, 14(6), pp 1-8.

12. Khalil H.P.S.A., Rozman H.D.,(2000), Rice-Husk Polyester Composites:The Effect of Chemical Modification of Rice Husk on the Mechanical and Dimensional Stability Properties, Polymer Plastic and Technology Engineering, 39, 757-781.

13. Tronc E., Hernandez-Escobar C.A., Ibarra-Gomez R., Estrada-Monje A.,NavarreteBolanos J., Zaragoza-Contreras E.A.,(2007),Blue Agave Fibre Esterification for the Reinforcement of Thermoplastic Composites,Carbohydrate Polymers,67,pp 245-255. 
14. EL-Tayeb N.S.M.,(2008),Abrasive Wear Performance of untreated Sugarcane Fibre Reinforced Polymer Composite, Material Processing Technology,206(1-3),pp 305314.

15. Habibi,Y., Heux,L., Mahrouz, M.and Vignon,M.R. (2008) Morphological and Structural Study of Seed Pericarp of Opuntia Ficus- Indica prickly Pear Fruits. Carbohydrate Polymers, 72(1), p102-112.

16. Sun J.X.,Sun X.F., Zhao H and Sun R.C. (2004) Isolation and Characterization of Cellulose from Sugarcane Bagasse. Polymer Degradation and Stability, 84(2), p331339.

17. Dotan A.L., Da Silva J.L.G., and Qureshi H.A.AL .,(1996), Macro and MicroMechanical Behaviour of Natural Fiber Composites, Mechanics in Design Conf., University of Toronto, Canada, 2, pp 823-831.

18. Egor P. Popov and Toader A. Balam (1991) Engineering Mechanics of Solids. $2^{\text {nd }}$ ed. Prentice Hall, Upper Saddle River, New Jersey, p68.

19. Amsted,B.H; Phillip;F. Ostwald and Myron L. Begeman (1987) Manufacturing Processes, John Wiley \& Sons, p287.

20. Bolton, W (1988) Production Technology- processes, materials and planning, Heinemann Professional Publishing, p122. 